Original Research Article

\title{
Analysis of adverse drug reactions of antimicrobial agents reported to ADR monitoring centre of a rural tertiary care teaching hospital
}

\author{
Bhaskar H. Nagaiah, Shivaraj Basavaraj Patil*, Nallavelly Vahila, Y. Venkata Rao, \\ Shrinivas R. Raikar, Mohd Sajid
}

\begin{abstract}
Department of Pharmacology, KIMS, Narketpally, Nalgonda District, Telangana, India
\end{abstract}

Received: 20 February 2017

Accepted: 28 March 2017

\section{*Correspondence to:}

Dr. Shivaraj Basavaraj Patil, Email:

shivarajpati185@gmail.com

Copyright: (C) the author(s), publisher and licensee Medip Academy. This is an openaccess article distributed under the terms of the Creative Commons Attribution NonCommercial License, which permits unrestricted noncommercial use, distribution, and reproduction in any medium, provided the original work is properly cited.

\begin{abstract}
Background: ADRs are iatrogenic diseases, escalates the burden of health care system by increasing the morbidity and mortality and also additional cost of ADRs management to patients.

Methods: A prospective observational study was conducted over 1 year from January 2015 to December 2015. The yellow forms dropped in the red ADR boxes are collected and ADRs due to antimicrobials were analyzed for demographic data, causality, severity, drugs implicated, and organ system affected. The data were presented as counts and percentages.

Results: Cephalosporins were the most common antimicrobial class implicated in ADRs, and the dermatological system was the most common system affected by ADRs. All the reactions either belonged to the probable or possible category. Majority of reactions were non-serious.

Conclusions: Regular prescription auditing and awareness about polypharmacy will further reduce ADRs due to antimicrobials.
\end{abstract}

Keywords: Antibiotics, Chemotherapeutic agents, Pharmacovigilance

\section{INTRODUCTION}

World Health Organisation (WHO) defined adverse drug reaction (ADR) as "a response to a drug which is noxious, and unintended, and which occurs at doses normally used in man for prophylaxis, diagnosis or therapy of disease, or for the modification of physiological function". ${ }^{1}$

ADRs are iatrogenic diseases, escalates the burden of health care system by increasing the morbidity and mortality and also additional cost of ADRs management to patients. Most of the ADRs of drugs are predictable from their pharmacology; hence health care system should take measures to minimise or to prevent them. Hospital admission due to ADRs varies from 4.2 to $30 \%$ USA and Canada, 5.7-18.8\% in Australia and 2.5-10.6\% in Europe. ADRs accounting for 1 in 16 hospital admission and of these $2 \%$ of patients are dying. ${ }^{2-5}$

Risks of ADRs are intrinsic of drugs and are modulated by various factors like dose, route and frequency of administrations, genotype, pharmacokinetic variations in geriatric and paediatric patients and impairment of heart, kidney and liver functions. ${ }^{3}$

In USA, the cost of ADR management is about 30.1 billion dollars annually. In India, no published reports available about the economic burden of ADRs. There is also increase in the cost of ADR management due to hospitalization, extending the stay of hospitalisation and clinical investigations of serious cases. Cost and ADRs can increase further with addition of new drugs for the management of existing ADRs of old drugs. ${ }^{3,4}$ 
WHO defined the Pharmacovigilance "the science and activities relating to the detection, assessment, understanding and prevention of adverse effects or any other possible drug-related problems". Pharmacovigilance is for patient care, helps to identify risks and risk factors of adverse drug effects and communicates to intelligent clinicians effectively and rapidly with evidence to minimise further injury and helps prevent most of the ADRs. ${ }^{6}$

India is a developing country; handling of infectious diseases is a major task, which causes high mortality and morbidity. Effective drugs are available for most of the infectious diseases but still mortality is high in children with respiratory and diarrheal diseases in developing countries. India has high burden of communicable diseases such as tuberculosis, human immunodeficiency virus/acquired immunodeficiency syndrome (HIV/AIDS), sexually transmitted diseases (STDs), malaria, schistosomiasis, amoebiasis, leprosy, trachoma, lymphatic filariasis, intestinal helminthiasis, leishmaniasis and trypanosomiasis. In developing countries because of poor infrastructure and transport facilities and to reduce mortality and morbidity of infectious diseases, public health programs (PHPs) administer drugs without adequate diagnosis for prophylaxis, treatment, mass therapy and also as presumptive treatment. ${ }^{6,7}$ Hence in this study, we attempted to identify ADRs due to antimicrobial agents, analyse their pattern, severity and causality.

\section{METHODS}

It was a prospective observational study conducted over one year from Jan 2015 to Dec 2015. Pharmacovigilance awareness lectures were frequently organised by pharmacovigilance cell for all health care professionals to motivate voluntary reporting of adverse drug reactions. The yellow ADR forms dropped in the red boxes were collected and analysed. Only those ADRs due to antimicrobials were included in the study. The yellow forms included information about patient initials, age, sex, diagnoses, name of suspected drug, route and frequency of administration of drug and signature of reporter. ADR forms were checked for completeness and the missing data was obtained by personally visiting the patient or going through the case sheets or consulting the treating physician. Prior ethics committee approval was obtained from the Institutional Ethics Committee. The causality assessment was done using the WHO scale by a special committee with two experts from pharmacology and clinician. ${ }^{8}$ The severity of reactions was assessed using Hartwig and Siegel scale. ${ }^{9}$ The data were analyzed and presented as numbers and percentages.

\section{RESULTS}

97 ADRs were reported due to antimicrobials to the pharmacovigilance centre.

\section{Demographics}

Most of the patients affected by ADRs were females i.e. $52(53.6 \%)$. The patients were distributed into various age groups (<11, 11-20,21-30,31-40,41-50,51-60,61-70, >70 years) (Figure 1) and most of them were in the age group of 21-30 i.e. $23(23.7 \%)$ followed by $31-40$ i.e. 22 $(22.7 \%)$.

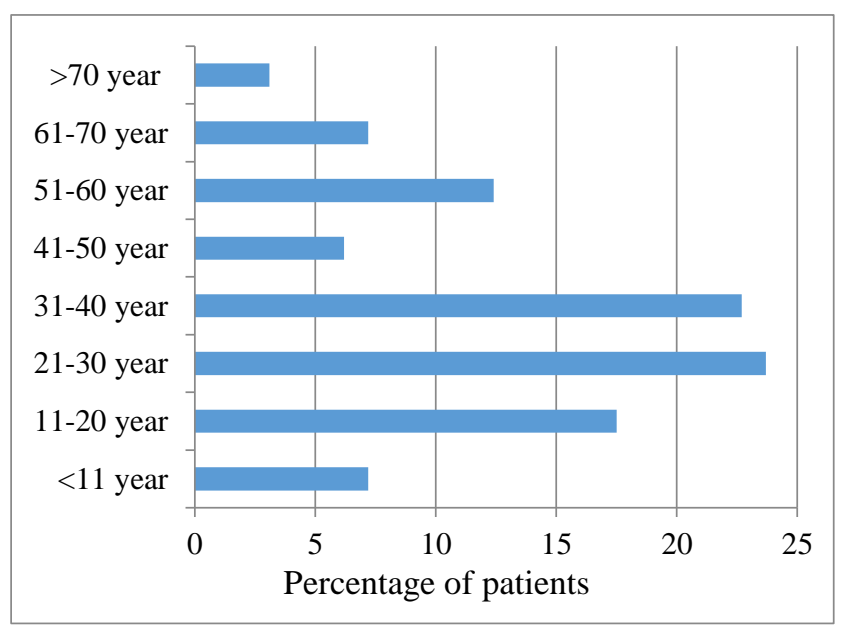

Figure 1: Age wise distribution of patients.

\section{Drugs causing ADRs}

Most common class of antimicrobials causing ADRs was Cephalosporins, followed by Anti-amoebic and Antiretroviral drugs (Table 1).

Table 1: Antimicrobial classes causing ADRs.

\begin{tabular}{|ll|}
\hline Antimicrobial classes & Percentage \\
\hline Cephalosporins & 24.7 \\
\hline Antiamoebic & 12.4 \\
\hline Antiretroviral drugs & 8.2 \\
\hline Fluoroquinolones & 6.2 \\
\hline Oxazolidinone & 5.2 \\
\hline Antitubercular drugs & 4.1 \\
\hline Others & 12.4 \\
\hline
\end{tabular}

Among Cephalosporins, Ceftriaxone was the most common drug implicated in ADRs.

\section{Table 2: Antimicrobial FDCs causing ADRs.}

\begin{tabular}{|ll|}
\hline Fixed dose combinations & Percentage \\
\hline Amoxicillin + clavulanic acid & 11.3 \\
\hline Piperacillin + tazobactam & 6.2 \\
\hline Ampicillin + cloxacillin & 3.1 \\
\hline Ofloxacin + ornidazole & 3.1 \\
\hline Cotrimoxazole & 1 \\
\hline Cefixime + ofloxacin & 1 \\
\hline
\end{tabular}

All the ADRs caused by Antiamoebic class were due to Metronidazole. Amoxicillin and clavulanic acid was the 
most common fixed dose combination antimicrobial implicated in ADRs (Table 2).

\section{Organ system involved in ADRs}

The most common system affected by ADRs was dermatological system $(41.2 \%)$ followed by the gastrointestinal system and musculoskeletal system (Figure 2).

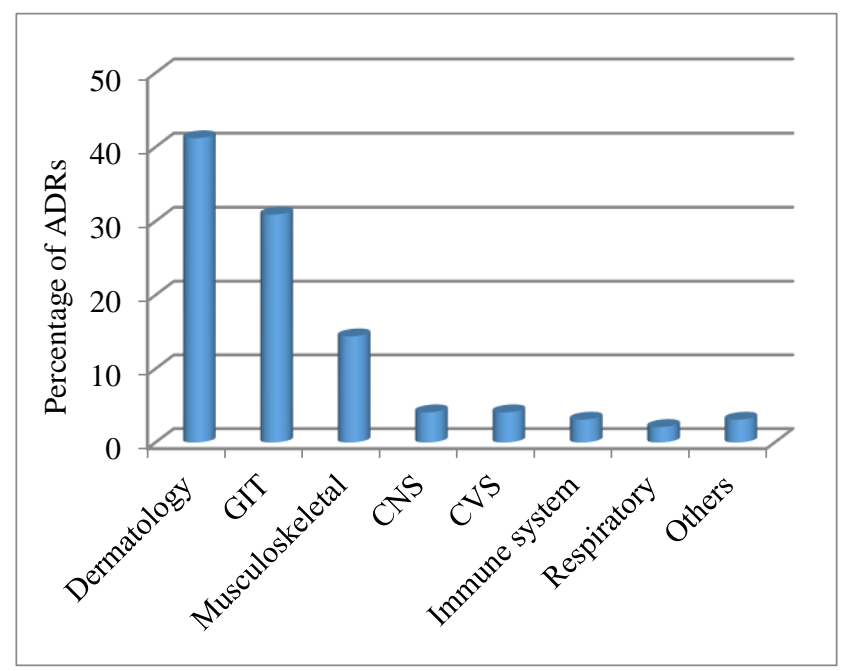

Figure 2: Organ system affected by ADRs.

\section{Severity of $A D R s$}

Most of the reactions were of mild to moderate severity (i.e. 94 ADRs) and 3 ADRs were of severe type (Figure 3).

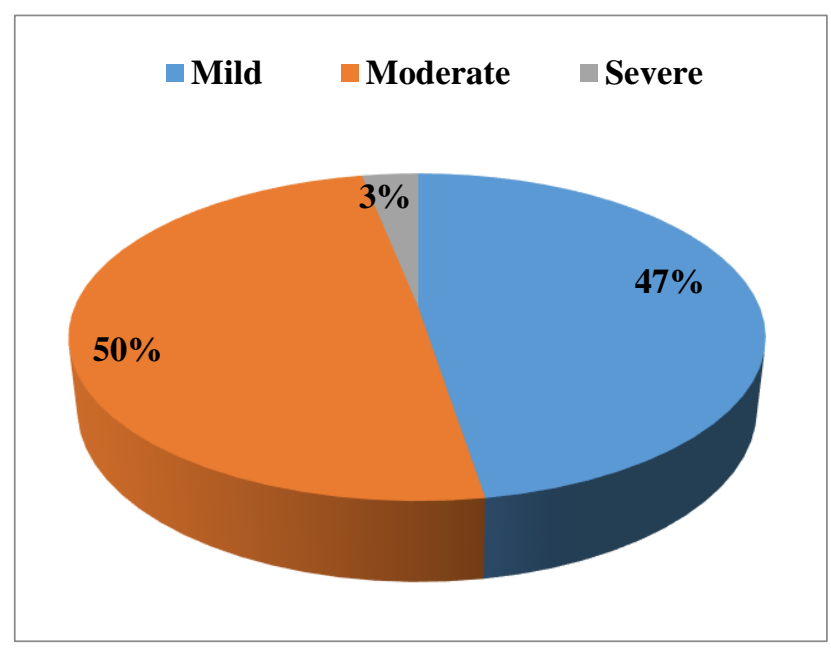

Figure 3: Severity of ADRs.

\section{Causality assessment}

WHO-UMC causality assessment scale was used for assessing the causality of ADRs. 79 ADRs were categorized as probable and 18 ADRs were categorized as possible.

\section{Action taken with the offending drug}

In most of the ADRs the offending drug was withdrawn. In 18 ADRs the offending drug was continued.

\section{DISCUSSION}

Infectious diseases are common in India and so the antimicrobials are used commonly to treat these infections. As long as they are used rationally they are considered safe drugs. But just like other drugs, they too produce adverse drug reactions.

In this study incidence of ADRs due to antimicrobials was slightly higher in females, which was similar to observation made by Swamy et al and Arulmani et al. ${ }^{10,11}$ Majority of patients affected were of adult age group which was similar to previous studies. ${ }^{12,13}$ The reason could be due to the fact that this adult population is the working class and more exposed to infectious diseases, so more chances of prescribing antimicrobials which increases the risk of ADRs.

Most common class of antimicrobials causing ADRs was Cephalosporins which is analogous to previous studies. ${ }^{12,14}$ Most common system affected by ADRs was dermatological system followed by gastrointestinal system which was in accordance to previous studies. ${ }^{13,15}$ The reason for increased reporting of dermatological reactions could be due to easy recognition of these reactions or extra cautious because of cosmetic reason.

Though majority of reactions were of mild to moderate severity, it increased the health care cost since it increased the length of stay in hospital and required some medical intervention. According to WHO causality assessment scale most of the reactions belonged to probable category followed by possible category. Re-challenge was not done considering the patient safety so no ADR was categorized as certain.

\section{CONCLUSION}

In this study adult females were most affected due to ADRs. Cephalosporins were the most common class implicated in ADRs and dermatological system was mostly affected. Regular prescription auditing and awareness about polypharmacy will further reduce ADRs due to antimicrobials.

\section{ACKNOWLEDGMENTS}

Author would like to thank national coordination center of PvPI, for providing technical associate to our ADR monitoring center. 
Funding: No funding sources

Conflict of interest: None declared

Ethical approval: The study was approved by the Institutional Ethics Committee

\section{REFERENCES}

1. WHO, Medicines areas quality safety efficacy Pharmacovigilance; 2016.

2. Pirmohamed M, James S, Meakin S, Green C, Scott AK, Walley TJ, et al. Adverse drug reactions as cause of admission to hospital: prospective analysis of 18820 patients BMJ. 2004;329(7456):15-9.

3. Janet S, Paola C, GianlucaT. Clinical and economic burden of adverse drug reactions. Journal of Pharmacology and Pharmacotherapeutics. 2013;4(1).

4. Kalisch LM, Caughey GE, Roughead RE, Gilbert AL. The prescribingcascade. Aust Prescr 2011;34:162-6.

5. Howard RL, Avery AJ, Slavenburg S, Royal S, Pipe $\mathrm{G}$, Lucassen P, et al. Which drugs cause preventable admissions to hospital? A systematic review. Br J Clin Pharmacol. 2007;63:136-47.

6. The Safety of Medicines in Public Health Programmes: Pharmacovigilance an essential tool, Publications of the World Health Organization; 2006.

7. Potkar CN, Kshirsagar NA, Kathuria R. Resurgence of malaria and medicine resistance in Plasmodium falciparum and Plasmodium vivax species in Bombay. Journal of Association of Physicians of India. 1995;43:336-8.

8. The Use of the WHO-UMC System for Standardised Case Causality Assessment; 2016:24734.

9. Hartwig SC, Siegel J, Schneider PJ. Preventability and severity assessment in reporting adverse drug reactions. Am J Hosp Pharm. 1992;49(9):2229-32.

10. Swamy S, Bhanuprakash, Nadig P, Muralimohan, Shetty M. Profile of suspect adverse drug reactions in a teaching tertiary care hospital. J Pharmacol Clin Toxicol. 2013;1(1):1005.

11. Arulmani R, Rajendran SD, Suresh B. Adverse drug reaction monitoring in a secondary care hospital in South India. Br J Clin Pharmacol. 2008;65(2):210-6.

12. Dhar K, Sinha A, Gaur P, Goel R, Chopra VS, Bajaj U. Pattern of adverse drug reactions to antibiotics commonly prescribed in department of medicine and pediatricss in a tertiary care teaching hospital, Ghaziabad. J App Pharm Sci. 2015;5(04):78-82.

13. Shrivastava M, Uchit G, Chakravarti A, Joshi G, Mahatme M, Chaudhari H. Adverse drug reactions reported in Indira Gandhi government medical college and hospital, Nagpur. J Assoc Physicians India. 2011;59:296-9.

14. Shamna M, Dilip C, Ajmal M, Mohan PL, Shinu C, Jafer CP, et al. A prospective study on Adverse Drug Reactions of antibiotics in a tertiary care hospital. Saudi pharmaceutical journal. 2014;30;22(4):303-8.

15. Hussain MM, Girhepunje K, Pal R, Siddiqua SS. Incidence of adverse drug reactions in a tertiary care hospital: a systematic review and meta-analysis of prospective studies. Der Pharmacia Lett. 2010;2(3):358-68.

Cite this article as: Nagaiah $\mathrm{BH}$, Patil SB, Vahila N, Rao YV, Raikar SR, Sajid M. Analysis of adverse drug reactions of antimicrobial agents reported to ADR monitoring centre of a rural tertiary care teaching hospital. Int J Basic Clin Pharmacol 2017;6:1151-4 